\title{
Synchronous Lumbar Disc Herniation in Adult Twins. Case Report
}

\author{
Ratan Bhardwaj, Rajiv Midha
}

\begin{abstract}
Objective: To report an unusual case of large synchronous lumbar disc herniation in adult twins. Methods: Case report and relevant literature review. Results: The authors report a case of adult female monozygotic twins who synchronously presented with huge lumbar disc herniation. Rather than being a curious coincidence, this case highlights the potential importance of hereditary factors in the causation of lumbar disc degeneration. The relevant literature regarding the role of genetic factors and their relationship to other risk factors in lumbar disc degeneration is reviewed and discussed. Conclusion: Synchronous lumbar disc herniation in adult twins is a rare event. It, however, sheds light on the role of genetic factors in disc degeneration.
\end{abstract}

RÉSUMÉ: Hernies discales lombaires synchrones chez des jumeaux adultes. Cas cliniques. Objectif : Rapporter un cas inusité d'importantes hernies discales lombaires synchrones chez des jumeaux adultes. Méthodes : Description de cas cliniques et revue de la littérature. Résultats : Les auteurs rapportent le cas de jumelles identiques qui ont présenté en même temps une hernie discale lombaire sévère. Plutôt que de le considérer simplement comme une coïncidence, ce cas illustre l'importance potentielle de facteurs héréditaires dans la dégénérescence discale lombaire. Nous revoyons la littérature et discutons du rôle de facteurs génétiques et de leur relation à d'autres facteurs de risque dans la dégénérescence discale lombaire. Conclusion : Une hernie discale lombaire survenant simultanément chez des jumeaux adultes est un événement rare qui peut faire la lumière sur le rôle de facteurs génétiques dans la dégénérescence discale.

Can. J. Neurol. Sci. 2004; 31: 554-557

Lumbar disc herniation has been previously reported in twin patient case reports in the adolescent population. ${ }^{1,2}$ Genetic links have also been postulated in the pathophysiology of disc herniation and spinal degenerative changes. ${ }^{3-9}$ However, this case is unique, since the disc herniation occurred synchronously in adult female twins within four months of each other. Another interesting factor is the fact that both twins demonstrated sacral lumbarization and the presence of a vestigial S1-S2 disc space.

\section{Case Report}

\section{Clinical Presentation}

The 52-year-old set of monozygotic female twins, of Caucasian background, presented with lower extremity pain within four months of each other. They are both non-smokers and hold office jobs. Twin \#1 (T1) initially complained of a bilateral aching hip pain, which then migrated down to both legs, but was worse on the left side. Her pain was exacerbated while walking and standing, and alleviated while lying in the curled position. Twin \#2 (T2) began to experience a severe, intractable pain radiating on her left side from her hip down to her foot. Three months later, T2 had a two week history of saddle anesthesia which then subsided, but was left with persistent paresthesias on her lateral left foot along with foot weakness. Neither twin experienced bowel or bladder symptoms.
T1 had normal power, tone, and bulk of her lower extremities. She had a decreased ankle tendon reflex on her right, with the other reflexes being normal. Her sensory exam was normal in all dermatomes. She had a positive straight leg raise at $45^{\circ}$ on her left and at $60^{\circ}$ on her right. T2 had profound left foot weakness (dorsiflexion 2/5, extensor hallicus longus $1 / 5$, and plantar flexion 4/5) and could not perform heel walking. Her sensation to pin prick was decreased in her left L5 to S3 dermatomes. Her left ankle tendon reflex was absent, with the others being normal. Her straight leg raise was positive at $45^{\circ}$ on the left and at $70^{\circ}$ on the right.

\section{Imaging}

A very large postero-centrally herniated L5-S1 disc is seen on T1's axial and sagittal MR images, severely compressing the dural sac (Figure 1A) and obscuring it (Figure 1B). An even larger herniated L5-

From the Division of Neurosurgery and Neuroscience Research Program, Sunnybrook $\&$ Women's College Health Sciences Centre, Department of Surgery, University of Toronto, Toronto, and Division of Neurosurgery, Department of Clinical

Neurosciences, University of Calgary, Calgary, AB, Canada

ReCeived DeCember 2, 2003. ACCePTed infinAlform May 25, 2004. Reprint requests to: Rajiv Midha, Division of Neurosurgery, Department of Clinical Neurosciences, University of Calgary, Foothills Medical Centre, 1403 - 29 Street N.W., Calgary, Alberta, Canada T2N 2T9 


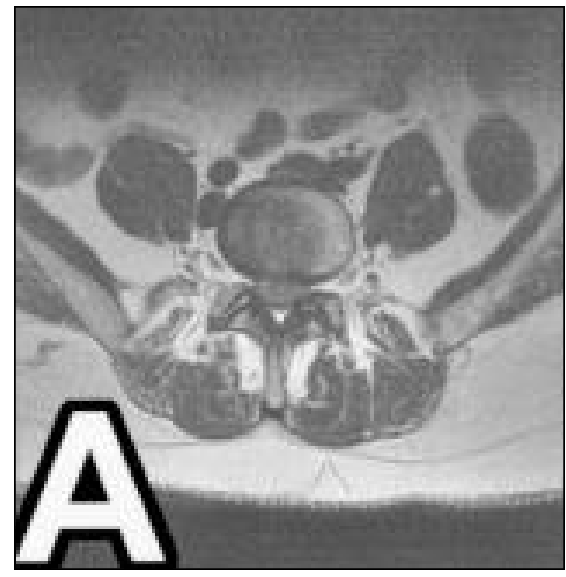

Figure 1A: Axial T2-weighted MR image at the L5-S1 disc space level of Twin \#1, demonstrating a large postero-central disc herniation. The disc is hard to distinguish from the severely compressed dural sac.
S1 disc, with a substantial left paracentral component, as well as upward migration behind the L5 vertebral body of a sequestrated component, is seen on T2's MR images (Figure 2). Postoperative antero-posterior plain radiography of the lumbar spine of both twins was performed and is shown in Figures 3Aand 3B, respectively. It is evident that the spinous process of L5 is absent in both studies, and that L5 is denoted as the 5th vertebrae counted below the 12th rib. In both figures, a disc space can be appreciated at the S1-S2 interspace. The sagittal MR images (Figures 1B and $2 \mathrm{~B}$ ) also demonstrate the substantial disc space present at the S1-S2 interspace, which is in keeping with sacral lumbarization.

\section{Operation}

T2 underwent a bilateral L5 laminectomy, left L5-S1 microdiscectomy and posterolateral decompression. Also removed was a large sequestered disc posterior and towards the left of the L5 vertebral body which was considerably compressing the left L5 nerve root. Following

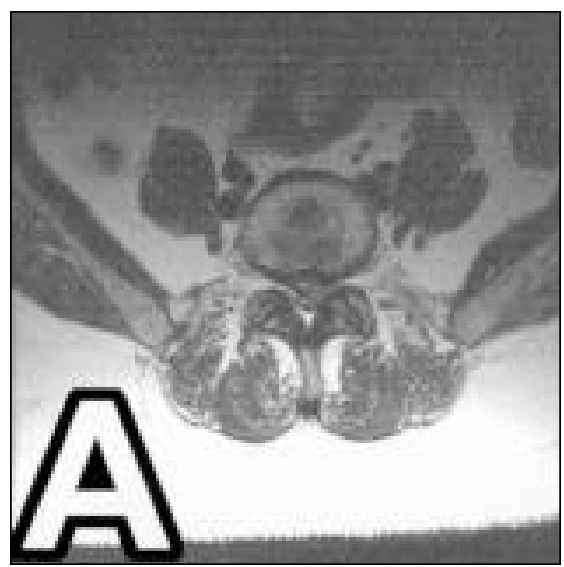

Figure 2A: Axial T2-weighted MR image at the L5-S1 disc space level of Twin \#2, demonstrating a massive left paracentral disc herniation.

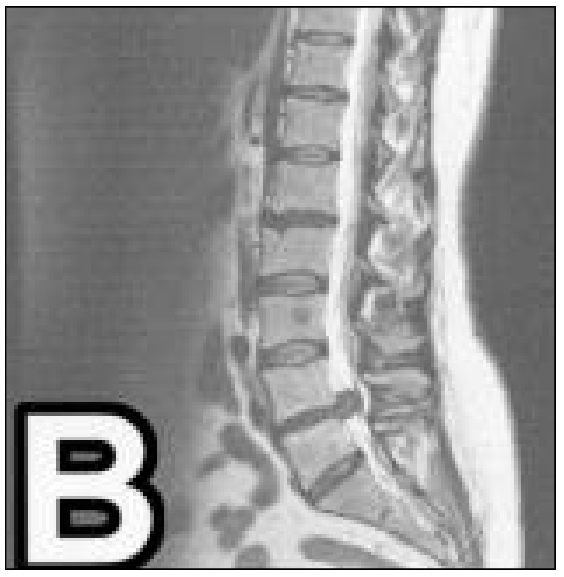

Figure 1B: Sagittal T2-weighted MR image of Twin \#1 demonstrating a large central disc herniation at the L5-S1 level, as well as a significant disc space at the S1-S2 level.

T2's surgery on the same day, T1 had a bilateral L5 laminectomy and left L5-S1 microdiscectomy.

\section{Postoperative Course}

Both twins had good postoperative courses. In both cases, their initial leg pain had abated, sciatica resolved and both remain pain-free in their legs at six month follow-up. Back pain persists somewhat in T1. The neurological exam was significantly improved in T2, with resolution of foot-drop and mild weakness (4/5) in ankle dorsiflexion and toe extension.

\section{DISCUSSION}

There have been cases of lumbar herniated discs in twins reported before, but this is the first case report of the occurrence in the adult population. ${ }^{1,3}$ A case report of four brothers offered a

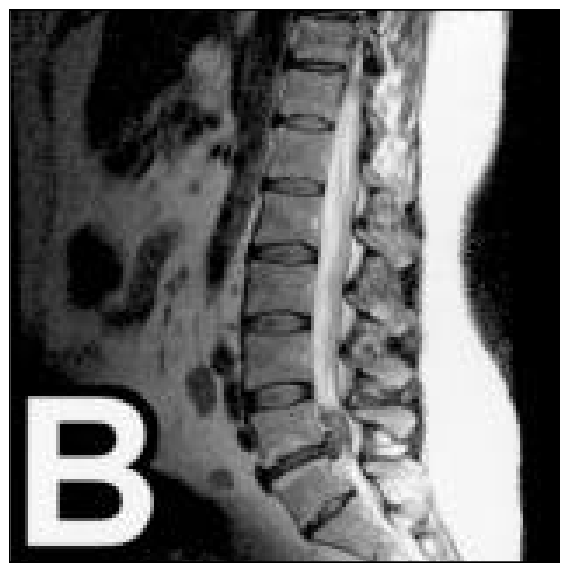

Figure 2B: Sagittal T2-weighted MR image of Twin \#2 showing a huge disc herniation at the L5-S1 level, with upward migration of a sequestered component, as well as a significant disc space at the S1-S2 level. 

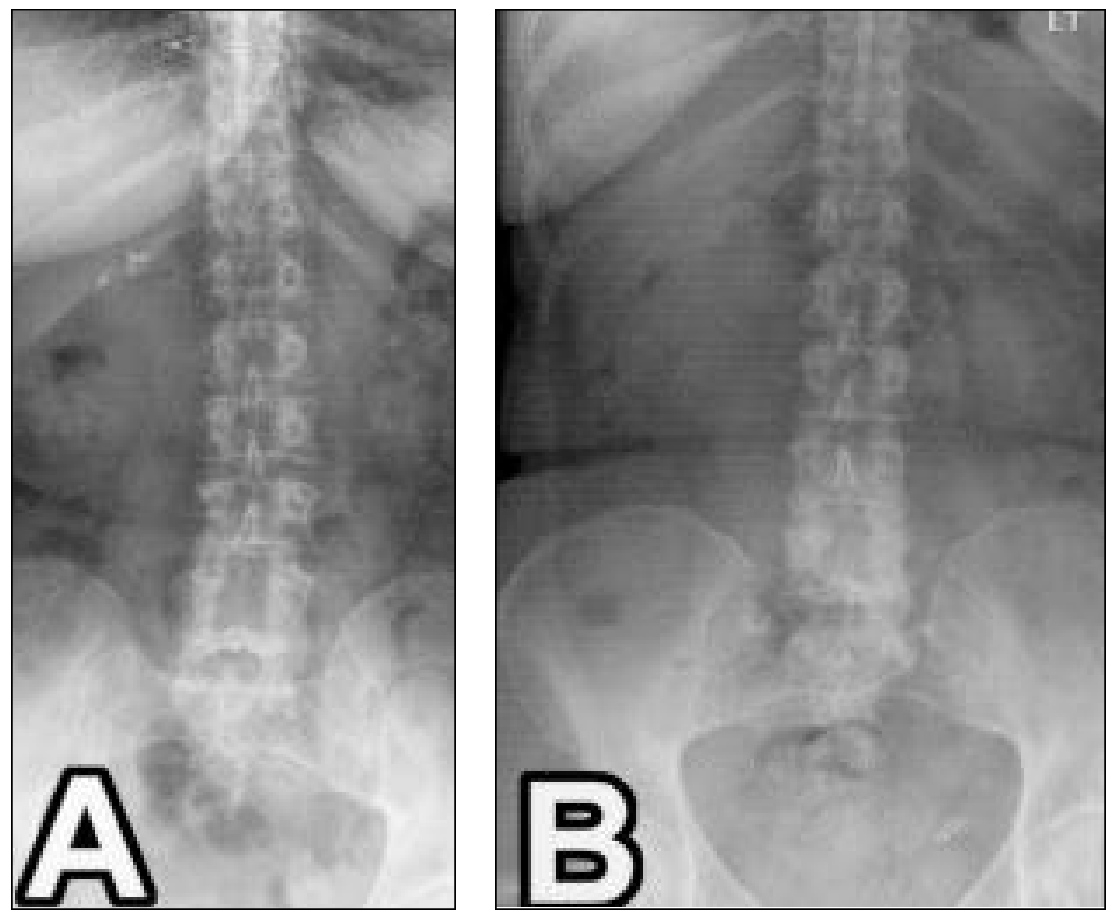

Figure $3 \boldsymbol{a} \& \boldsymbol{b}$ : Postoperative antero-posterior plain radiography of the lumbar spine of Twins 1 and 2, respectively, showing that the spinous processes of L5 (or the 5th vertebral body below the 12th rib) was resected in both cases.

description which implicated that developmental or hereditary factors may be responsible for spinal stenosis and lumbar disc herniation. ${ }^{10}$ In all of these reports, the onset of symptoms occurred prior to the age of twenty. A familial predisposition and clustering for juvenile lumbar disc herniation has been demonstrated in one study, with an odds ratio of 5.61 in comparison to the controls. ${ }^{7}$ The family predisposition has been suggested by another study in the adult population, where a family history of operated lumbar disc herniation in juvenile family members had a significant implication in lumbar degenerative disc disease in their adult relatives compared to an age-matched control population. ${ }^{6}$ Moreover, this study demonstrated that a characteristic of familial lumbar disc degeneration is that the disc pathology tends to be at the same level, ${ }^{6}$ as also seen in our case.

This case is unique since the twins were in their adult years when they suffered the disc herniation. Another curious factor is that both twins herniated synchronously within four months of the other. This would imply that they had the predisposition for lumbar disc herniation at the same L5-S1 level, but that they did not actually herniate until they were in their fifties. In a large Finnish twin panel study consisting of 9,365 adult pairs of the same gender, the genetic predisposition to symptomatic lumbar disc herniation and sciatica manifested largely before the age of 40, while after this environmental factors assumed much greater importance. ${ }^{5}$ Based on this information and the subsequent discussion on the relative role of genetic and environmental factors, one can conclude that lumbar disc disease is clearly multifactorial, with hereditary predisposition increasingly shaped by environmental consideration as the person ages.

There have been many environmental factors postulated in the pathogenesis of lumbar disc herniation, including aging, mechanical injuries, degenerative changes, smoking, obesity and atherosclerosis. ${ }^{5,9}$ However, well-controlled cohort twin studies indicate that these environmental factors are not nearly as important when compared to genetic influences. ${ }^{3,4,9}$ For example, Battie et $\mathrm{al}^{3}$ found that smoking status and age explained, at most, $15 \%$ of the variability in explaining disc degeneration assessed by MRI, while $26-72 \%$ of the variability was attributable to a variable representing co-twin status. In another study, the same group, using a multivariate analysis model, determined that both age and occupational or leisure factors associated with heavy (as opposed to lesser) load on the spine had minimal impact on the variability associated with disc degeneration, as contrasted to familial aggregation, which explained much more of the variability. ${ }^{4}$

While phenotypic variables have been well-reported supporting the genetic predisposition to lumbar disc degeneration, the association of genotypic factors has been raised only recently. ${ }^{9}$ From the population-based Finnish twin cohort, 85 pairs of male monozygotic twins were selected and correlation between MR T2 weighted signal intensity (of disc degeneration) and two polymorphisms of the coding region of the vitamin D receptor locus sought. The study revealed that two specific vitamin D receptor alleles were significantly associated with intervertebral disc degeneration. ${ }^{9}$ This report further supports the 
role of genetic factors of disc degeneration in the adult population.

\section{ACKNOWLEDGEMENT}

The authors thank Ms. Catherine Munro and Mr. Jason Belkas for their assistance with preparation of the figures and the manuscript.

\section{REFERENCES}

1. Gunzburg R, Fraser RD, Fraser GA. Lumbar intervertebral disc prolapse in teenage twins. A case report and review of the literature. J Bone Joint Surg Br 1990;72(5):914-916.

2. Matsui $\mathrm{H}$, Tsuji $\mathrm{H}$, Terahata N. Juvenile lumbar herniated nucleus pulposus in monozygotic twins. Spine 1990;15(11):1228-1230.

3. Battie MC, Haynor DR, Fisher LD, et al. Similarities in degenerative findings on magnetic resonance images of the lumbar spines of identical twins. J Bone Joint Surg (Am) 1995;77(11):1662-1670.

4. Battie MC, Videman T, Gibbons LE, et al. 1995 Volvo Award in Clinical Sciences. Determinants of lumbar disc degeneration. A study relating lifetime exposures and magnetic resonance imaging findings in identical twins. Spine 1995;20(24):26012612.

5. Heikkila JK, Koskenvuo M, Heliovaara M, et al. Genetic and environmental factors in sciatica. Evidence from a nationwide panel of 9365 adult twin pairs. Ann Med 1989;21(5):393-398.

6. Matsui $\mathrm{H}$, Kanamori M, Ishihara $\mathrm{H}$, et al. Familial predisposition for lumbar degenerative disc disease. A case-control study. Spine 1998;23(9):1029-1034.

7. Matsui H, Terahata N, Tsuji H, Hirano N, Naruse Y. Familial predisposition and clustering for juvenile lumbar disc herniation. Spine 1992;17(11):1323-1328.

8. Sambrook PN, MacGregor AJ, Spector TD. Genetic influences on cervical and lumbar disc degeneration: a magnetic resonance imaging study in twins. Arthritis Rheum 1999;42(2):366-372.

9. Videman T, Leppavuori J, Kaprio J, et al. Intragenic polymorphisms of the vitamin D receptor gene associated with intervertebral disc degeneration. Spine 1998;23(23):2477-2485.

10. Varughese G, Quartey GR. Familial lumbar spinal stenosis with acute disc herniations. Case reports of four brothers. J Neurosurg 1979;51(2):234-236. 